\title{
Positron Emission Mammography
}

National Cancer Institute

\section{Source}

National Cancer Institute. Positron Emission Mammography. NCI Thesaurus. Code

C116559.

An imaging technique that utilizes a radiolabeled sugar given intravenously to help define the size, shape, and location of a breast tumor. 